\title{
Symmetric decompositions of cost variation ${ }^{\text {is }}$
}

\author{
Bert M. Balk ${ }^{\mathrm{a}, *}$, José L. Zofío ${ }^{\mathrm{b}, \mathrm{c}}$ \\ a Rotterdam School of Management, Erasmus University, the Netherlands \\ ${ }^{\mathrm{b}}$ Department of Economics, Universidad Autónoma de Madrid, Spain \\ ${ }^{\mathrm{c}}$ Erasmus Research Institute of Management, Erasmus University, the Netherlands
}

\section{A R T I C L E I N F O}

\section{Article history:}

Received 15 June 2019

Accepted 19 February 2020

Available online 26 February 2020

\section{Keywords:}

Productivity and competitiveness

Cost variation

Decomposition

Efficiency change

Technological change

\begin{abstract}
A B S T R A C T
In this paper a number of symmetric, empirically implementable decompositions of the cost variation (in difference and ratio form) of a production unit are developed. The components distinguished are price level change, technical efficiency change, allocative efficiency change, technological change, scale of activity change, and price structure change. Given data from a (balanced) panel of production units, all the necessary ingredients for the computation of the various decompositions can be obtained by using linear programming techniques (DEA). An application is provided.
\end{abstract}

(C) 2020 Elsevier B.V. All rights reserved.

\section{Introduction}

Though textbook theory generally introduces production units as being profit maximizers, it turns out that usually they have more control over their inputs than over their outputs. Any attempt to raise output quantities or revenue (if there is a market for outputs) can break down at unexpected events, such as a sudden drop in the demand for the unit's products, changes in regulatory regime, and natural or technical disasters. (Think these days of suppliers to Boeing who, by the 737 Max crisis, saw their output markets vanish!) On the contrary, the input side seems to be more malleable and a cost decrease seems a management target that may be easier to attain than a revenue increase.

However, suppose that over a certain span of years a production unit succeeds to decrease its cost, can one then ascribe this result entirely to the role of management? That would be too simple a conclusion as also at the input side there are factors beyond the control of management. Thus, it appears worthwhile to be able to discriminate between the various factors influencing cost variation,

\footnotetext{
This paper has been presented at the XVI European Workshop on Efficiency and Productivity Analysis, London, 10-13 June 2019. A preliminary version of the theoretical part was presented at the North American Productivity Workshop at Union College, Schenectady NY, 15-17 June 2000. We thank participants of the research seminar at the Center for Operations Research, Elche (Alicante), Spain, 7 November 2019, for comments and suggestions. We are also grateful to three referees. José L. Zofío acknowledges support from the Spanish Ministry for Economy and Competitiveness under grant MTM2016-79765-P.

* Corresponding author.

E-mail addresses: bbalk@rsm.nl (B.M. Balk), jose.zofio@uam.es (J.L. Zofío).
}

whether they are under management's control or not. This is the theme of the present paper.

The first task is to separate the effect of prices from the effect of quantities. As cost variation can be presented as a difference (in monetary terms) or a ratio, we must make a distinction between additive measures, called indicators, and multiplicative measures, called indices. The second task is to delve deeper into the sources of input quantity change. Again, textbook theory generally considers input quantity change as being endogenous, caused by exogenous factors such as technological change, output quantity change, or input price change. This, however, tacitly presupposes efficient behaviour by (the management of) the production unit. Accounting for possibly inefficient behaviour implies that two additional factors come into play, namely technical and allocative efficiency. Separating all these effects is possible if the researcher is equipped with quantifiable information about the technologies in which the production unit under consideration operates.

The literature provides a number of such decompositions. However, as will be shown below, they appear to be asymmetric. What do we mean by that? The classic example is the measurement of price change, quantity change, and value change between two periods. For the measurement of price change and quantity change one may use the former period viewpoint, giving rise to Laspeyres indices (if one likes ratio-type measures) or indicators (if one likes difference-type measures). Alternatively, one may use the later period viewpoint, giving rise to Paasche indices or indicators. Fine! But when it comes to decomposing value change into the two components, prices and quantities, we are meeting a problem. A Laspeyres price index or indicator goes only with a Paasche quantity index or indicator, and vice versa. Hence, by restricting our 
measurement tools to only Laspeyres and Paasche, any decomposition of value change contains a mix of viewpoints, which is what we will call asymmetric. Of course, there may be good reasons for using an asymmetric decomposition, but in the absence of such reasons, we would prefer a symmetric one. In the classic example this is provided by using Fisher indices or Bennet indicators.

The core contribution of the present paper is to provide a number of symmetric decompositions for cost variation and, for the first time, to compare all the decompositions, symmetric as well as asymmetric, on a real-life dataset of production units.

The plan of the paper follows from this outline. After having provided the necessary definitions in Section 2, Section 3 discusses additive decompositions, Section 4 discusses multiplicative decompositions, and Section 5 some alternatives. Section 6 contains the application. Section 7 concludes.

\section{The setting}

We consider a single production unit (henceforth called firm), producing output quantities $y^{t}$ while employing input quantities $x^{t}$ at input prices $w^{t}(t=0,1)$. Generic output quantity, input quantity and input price vectors will be denoted by $y \in \Re_{+}^{M}, x \in \Re_{+}^{N}$ and $w \in \Re_{++}^{N}$ respectively. Assuming the usual regularity conditions, the period $t$ technology can be represented by the radial input distance function $D_{i}^{t}(x, y)$ or the cost function $C^{t}(w, y)$. The cost-minimizing input quantity vector will be denoted by $x^{t}(w, y)$, so that $C^{t}(w, y)=w \cdot x^{t}(w, y)$, where - denotes the inner product of two equally dimensioned vectors. Notice that $x^{t}(w, y)$ is homogeneous of degree 0 in input prices $w$, and thus depends only on relative input prices or the input price structure. ${ }^{1}$

We are in this paper concerned with the cost variation between periods 0 and 1 , which can be expressed ${ }^{2}$ additively as $w^{1} \cdot x^{1}-$ $w^{0} \cdot x^{0}$, and multiplicatively as $w^{1} \cdot x^{1} / w^{0} \cdot x^{0}$.

\section{An additive decomposition}

The cost variation can be decomposed additively as

$w^{1} \cdot x^{1}-w^{0} \cdot x^{0}=\frac{1}{2}\left(x^{0}+x^{1}\right) \cdot\left(w^{1}-w^{0}\right)+\frac{1}{2}\left(w^{0}+w^{1}\right) \cdot\left(x^{1}-x^{0}\right)$,

where the first term on the right-hand side is the Bennet input price indicator and the second term is the Bennet input quantity indicator (see Balk, 2008 for definitions and properties). GrifellTatjé and Lovell (2000) proposed to decompose the vector of input quantity differences as

$x^{1}-x^{0}=\left(x^{1}-\frac{x^{1}}{D_{i}^{1}\left(x^{1}, y^{1}\right)}\right)-\left(x^{0}-\frac{x^{0}}{D_{i}^{0}\left(x^{0}, y^{0}\right)}\right)+$

$\left(\frac{x^{1}}{D_{i}^{1}\left(x^{1}, y^{1}\right)}-x^{1}\left(w^{1}, y^{1}\right)\right)-\left(\frac{x^{0}}{D_{i}^{0}\left(x^{0}, y^{0}\right)}-x^{0}\left(w^{0}, y^{0}\right)\right)+$

$x^{1}\left(w^{1}, y^{0}\right)-x^{0}\left(w^{0}, y^{0}\right)+$

$x^{1}\left(w^{1}, y^{1}\right)-x^{1}\left(w^{1}, y^{0}\right)$.

The first part on the right-hand side, expression (2), is a difference of two terms of the form $x^{t}-x^{t} / D_{i}^{t}\left(x^{t}, y^{t}\right)$. The last expression is the difference between the vector of actual input quantities and the vector of technically efficient input quantities which

\footnotetext{
1 If the cost function is continuously differentiable, then by Shephard's Lemma $x^{t}(w, y)=\nabla_{w} C^{t}(w, y)$, the vector of first-order derivatives with respect to $w$.

2 It is assumed that the periods are not too far apart, so that it is meaningful to compare money amounts. If not, an adjustment for general inflation might be necessary.
}

is obtained by radially contracting the first vector to the technological frontier. The expression $x^{t}-x^{t} / D_{i}^{t}\left(x^{t}, y^{t}\right)$ is thus a measure of technical efficiency in quantity units, and the difference of these expressions signifies technical efficiency change. Following GrifellTatjé and Lovell (2000), the inner product of expression (2) and $\frac{1}{2}\left(w^{0}+w^{1}\right)$ will be called the technical efficiency effect. It is a measure of technical efficiency change in monetary units.

The second part on the right-hand side, expression (3), is a difference of two terms of the form $x^{t} / D_{i}^{t}\left(x^{t}, y^{t}\right)-x^{t}\left(w^{t}, y^{t}\right)$. The last expression is the difference between the vector of technically efficient input quantities and the vector of cost minimizing input quantities. The expression $x^{t} / D_{i}^{t}\left(x^{t}, y^{t}\right)-x^{t}\left(w^{t}, y^{t}\right)$ is thus a measure of allocative efficiency in quantity units, and the difference of these expressions signifies whether the firm's allocative efficiency has bettered or worsened. Again following Grifell-Tatjé and Lovell (2000), the inner product of expression (3) and $\frac{1}{2}\left(w^{0}+w^{1}\right)$ will be called the allocative efficiency effect. It measures allocative efficiency change in monetary units.

Grifell-Tatjé and Lovell (2000) called the inner product of expression (4) and $\frac{1}{2}\left(w^{0}+w^{1}\right)$ the technological change effect, and the inner product of expression (5) and $\frac{1}{2}\left(w^{0}+w^{1}\right)$ the activity effect.

However, it is immediately clear from the functional structure, first, that expression (4) in fact combines the effect of technological change (as represented by the difference between the costminimizing input quantity vectors under the two technologies, $x^{1}(w, y)$ and $\left.x^{0}(w, y)\right)$ and the effect of differing input price structures between the periods 0 and $1 .^{3}$ Second, the combined effect appears to condition only on the period 0 output quantity vector $y^{0}$. In contrast, the activity effect term, expression (5), conditions on the period 1 technology (via $x^{1}(w, y)$ ) as well as the period 1 input price structure. Thus the entire decomposition exhibits an asymmetry as explained in the Introduction.

A similar decomposition was employed by Brea-Solís, Casadesus-Masanell, and Grifell-Tatjé (2015). ${ }^{4}$ Their technical efficiency effect was the same as above, but the remainder

$$
\frac{x^{1}}{D_{i}^{1}\left(x^{1}, y^{1}\right)}-\frac{x^{0}}{D_{i}^{0}\left(x^{0}, y^{0}\right)}
$$

was split into (alternatively defined) activity and technological change effects. However, both effects exhibited also asymmetries.

It appears that a fully symmetric decomposition can be obtained by combining the last two parts, expressions (4) and (5), and decomposing the result into three symmetrical parts, as follows:

$$
\begin{aligned}
& x^{1}\left(w^{1}, y^{1}\right)-x^{0}\left(w^{0}, y^{0}\right) \\
& \quad=\frac{1}{2}\left[x^{1}\left(w^{1}, y^{1}\right)-x^{0}\left(w^{1}, y^{1}\right)+x^{1}\left(w^{0}, y^{0}\right)-x^{0}\left(w^{0}, y^{0}\right)\right]+
\end{aligned}
$$

$$
\begin{gathered}
\frac{1}{4}\left[x^{1}\left(w^{1}, y^{1}\right)-x^{1}\left(w^{1}, y^{0}\right)+x^{1}\left(w^{0}, y^{1}\right)-x^{1}\left(w^{0}, y^{0}\right)+\right. \\
\left.x^{0}\left(w^{1}, y^{1}\right)-x^{0}\left(w^{1}, y^{0}\right)+x^{0}\left(w^{0}, y^{1}\right)-x^{0}\left(w^{0}, y^{0}\right)\right]+
\end{gathered}
$$

$$
\begin{gathered}
\frac{1}{4}\left[x^{1}\left(w^{1}, y^{1}\right)-x^{1}\left(w^{0}, y^{1}\right)+x^{1}\left(w^{1}, y^{0}\right)-x^{1}\left(w^{0}, y^{0}\right)+\right. \\
\left.x^{0}\left(w^{1}, y^{1}\right)-x^{0}\left(w^{0}, y^{1}\right)+x^{0}\left(w^{1}, y^{0}\right)-x^{0}\left(w^{0}, y^{0}\right)\right]
\end{gathered}
$$

\footnotetext{
3 To overcome the combination, Grifell-Tatjé and Lovell $(2015,289)$ decomposed expression (4) as $\left(x^{1}\left(w^{1}, y^{0}\right)-x^{1}\left(w^{0}, y^{0}\right)\right)+\left(x^{1}\left(w^{0}, y^{0}\right)-x^{0}\left(w^{0}, y^{0}\right)\right)$, measuring the input substitution effect and the technological change effect, respectively. The resulting five-components decomposition was applied by Reyna and Fuentes (2018).

${ }^{4}$ These authors actually considered profit variation $\left(p^{1} \cdot y^{1}-w^{1} \cdot x^{1}\right)-\left(p^{0} \cdot y^{0}-\right.$ $\left.w^{0} \cdot x^{0}\right)$, where $p^{t}(t=0,1)$ are output prices. The restriction to cost variation is obvious.
} 
The first part, expression (6), when multiplied by $\frac{1}{2}\left(w^{0}+\right.$ $\left.w^{1}\right)$, measures the technological change effect in monetary terms. The second part, expression (7), is the average of $x^{t}\left(w^{t^{\prime}}, y^{1}\right)-$ $x^{t}\left(w^{t^{\prime}}, y^{0}\right)$ over the four possible combinations of $t, t^{\prime}=0,1$. It measures the activity effect (scale of operation of the firm). The third part, expression (8), similarly measures the effect of differing input price structures. One sees immediately that if there is no technological change, that is, $x^{t}(w, y)=x(w, y)(t=0,1)$, then the first part vanishes and the other two parts reduce to

$\frac{1}{2}\left[x\left(w^{1}, y^{1}\right)-x\left(w^{1}, y^{0}\right)+x\left(w^{0}, y^{1}\right)-x\left(w^{0}, y^{0}\right)\right]$

and

$\frac{1}{2}\left[x\left(w^{1}, y^{1}\right)-x\left(w^{0}, y^{1}\right)+x\left(w^{1}, y^{0}\right)-x\left(w^{0}, y^{0}\right)\right]$,

respectively.

Thus, combining expressions (1)-(3), (6)-(8), we have obtained an additive decomposition of the cost variation $w^{1} \cdot x^{1}-w^{0} \cdot x^{0}$ into six effects, respectively that of input prices,

$\frac{1}{2}\left(x^{0}+x^{1}\right) \cdot\left(w^{1}-w^{0}\right)$,

technical efficiency,

$\frac{1}{2}\left(w^{0}+w^{1}\right) \cdot\left(\left(x^{1}-\frac{x^{1}}{D_{i}^{1}\left(x^{1}, y^{1}\right)}\right)-\left(x^{0}-\frac{x^{0}}{D_{i}^{0}\left(x^{0}, y^{0}\right)}\right)\right)$,

allocative efficiency,

$$
\begin{aligned}
& \frac{1}{2}\left(w^{0}+w^{1}\right) \cdot\left(\left(\frac{x^{1}}{D_{i}^{1}\left(x^{1}, y^{1}\right)}-x^{1}\left(w^{1}, y^{1}\right)\right)\right. \\
& \left.-\left(\frac{x^{0}}{D_{i}^{0}\left(x^{0}, y^{0}\right)}-x^{0}\left(w^{0}, y^{0}\right)\right)\right),
\end{aligned}
$$

technological change,

$$
\frac{1}{4}\left(w^{0}+w^{1}\right) \cdot\left[x^{1}\left(w^{1}, y^{1}\right)-x^{0}\left(w^{1}, y^{1}\right)+x^{1}\left(w^{0}, y^{0}\right)-x^{0}\left(w^{0}, y^{0}\right)\right],
$$

activity (scale of operation),

$$
\begin{aligned}
& \frac{1}{8}\left(w^{0}+w^{1}\right) \cdot\left[x^{1}\left(w^{1}, y^{1}\right)-x^{1}\left(w^{1}, y^{0}\right)+x^{1}\left(w^{0}, y^{1}\right)-x^{1}\left(w^{0}, y^{0}\right)+\right. \\
& \left.x^{0}\left(w^{1}, y^{1}\right)-x^{0}\left(w^{1}, y^{0}\right)+x^{0}\left(w^{0}, y^{1}\right)-x^{0}\left(w^{0}, y^{0}\right)\right],
\end{aligned}
$$

and input price structure,

$$
\begin{aligned}
& \frac{1}{8}\left(w^{0}+w^{1}\right) \cdot\left[x^{1}\left(w^{1}, y^{1}\right)-x^{1}\left(w^{0}, y^{1}\right)+x^{1}\left(w^{1}, y^{0}\right)-x^{1}\left(w^{0}, y^{0}\right)+\right. \\
& \left.x^{0}\left(w^{1}, y^{1}\right)-x^{0}\left(w^{0}, y^{1}\right)+x^{0}\left(w^{1}, y^{0}\right)-x^{0}\left(w^{0}, y^{0}\right)\right] .
\end{aligned}
$$

If in both periods the firm is technically efficient then the technical efficiency effect vanishes. If in both periods the firm is allocatively efficient then the allocative efficiency effect vanishes. If in both periods the firm is cost efficient then both effects vanish. Technological progress (regress) occurs if the technological change effect is negative (positive). If the scale of operation does not change, $y^{1}=y^{0}$, then the activity effect vanishes.

Although it seems that the input price structure effect is double-counted, as price structure is part of the prices as occurring in the input price effect, this is superficial. Input prices exert a two-fold effect on the cost variation, a direct (level) effect as measured by expression (11), and an indirect (structure) effect, running via the cost-minimizing input quantities, as measured by expression (16). If $w^{1}=\lambda w^{0}$ for some $\lambda>0$, then the input price structure effect vanishes but the input price effect itself not.

Combining expressions (12) and (13) delivers

$\frac{1}{2}\left(w^{0}+w^{1}\right) \cdot\left(\left(x^{1}-x^{1}\left(w^{1}, y^{1}\right)\right)-\left(x^{0}-x^{0}\left(w^{0}, y^{0}\right)\right)\right)$, which measures the joint effect of technical and allocative efficiency change. This, however, should not be confused with cost efficiency change as such. A natural, additive measure of cost efficiency at period $t$ is $C^{t}\left(w^{t}, y^{t}\right)-w^{t} \cdot x^{t}$, which is less than or equal to 0 , a larger magnitude indicating more efficiency. Thus cost efficiency change, going from period 0 to period 1 , is measured by $\left(C^{1}\left(w^{1}, y^{1}\right)-w^{1} \cdot x^{1}\right)-\left(C^{0}\left(w^{0}, y^{0}\right)-w^{0} \cdot x^{0}\right)$. Using the cost function definition, this can be rewritten as

$w^{1} \cdot\left(x^{1}\left(w^{1}, y^{1}\right)-x^{1}\right)-w^{0} \cdot\left(x^{0}\left(w^{0}, y^{0}\right)-x^{0}\right)$.

Comparing expressions (17) and (18) we see that not only their sign differs, but also that the last expression includes the full effect of price level change between periods 0 and 1 .

\section{A multiplicative decomposition}

A multiplicative counterpart to expression (1) is provided by a decomposition in terms of Sato-Vartia price and quantity indices (see Balk, 2008 for definitions and properties),

$\frac{w^{1} \cdot x^{1}}{w^{0} \cdot x^{0}}=\prod_{n=1}^{N}\left(w_{n}^{1} / w_{n}^{0}\right)^{\phi_{n}^{01}} \times \prod_{n=1}^{N}\left(x_{n}^{1} / x_{n}^{0}\right)^{\phi_{n}^{01}}$,

where

$\phi_{n}^{01} \equiv \frac{L M\left(s_{n}^{0}, s_{n}^{1}\right)}{\sum_{n=1}^{N} L M\left(s_{n}^{0}, s_{n}^{1}\right)}(n=1, \ldots, N)$,

$s_{n}^{t} \equiv w_{n}^{t} x_{n}^{t} / w^{t} \cdot x^{t}(n=1, \ldots, N ; t=0,1)$,

and $\operatorname{LM}(a, b)$ is the logarithmic mean. ${ }^{5}$ Following the logic of the previous section, the quantity index can be decomposed multiplicatively as

$\prod_{n=1}^{N}\left(x_{n}^{1} / x_{n}^{0}\right)^{\phi_{n}^{01}}=\prod_{n=1}^{N}\left(\frac{x_{n}^{1} / x_{n}^{1}\left(w^{1}, y^{1}\right)}{x_{n}^{0} / x_{n}^{0}\left(w^{0}, y^{0}\right)}\right)^{\phi_{n}^{01}} \times \prod_{n=1}^{N}\left(\frac{x_{n}^{1}\left(w^{1}, y^{1}\right)}{x_{n}^{0}\left(w^{0}, y^{0}\right)}\right)^{\phi_{n}^{01}}=$

$$
\begin{aligned}
& \prod_{n=1}^{N}\left(\frac{\frac{x_{n}^{1}}{x_{n}^{1} / D_{i}^{1}\left(x^{1}, y^{1}\right)}}{\frac{x_{n}^{0}}{x_{n}^{0} / D_{i}^{0}\left(x^{0}, y^{0}\right)}}\right)^{\phi_{n}^{01}} \times \prod_{n=1}^{N}\left(\frac{\frac{x_{n}^{1} / D_{i}^{1}\left(x^{1}, y^{1}\right)}{x_{n}^{1}\left(w^{1}, y^{1}\right)}}{\frac{x_{n}^{0} / D_{i}^{0}\left(x^{0}, y^{0}\right)}{x_{n}^{0}\left(w^{0}, y^{0}\right)}}\right)^{\phi_{n}^{01}} \times \prod_{n=1}^{N}\left(\frac{x_{n}^{1}\left(w^{1}, y^{1}\right)}{x_{n}^{0}\left(w^{0}, y^{0}\right)}\right)^{\phi_{n}^{01}} \\
& =\frac{D_{i}^{1}\left(x^{1}, y^{1}\right)}{D_{i}^{0}\left(x^{0}, y^{0}\right)} \times \prod_{n=1}^{N}\left(\frac{\frac{x_{n}^{1} / D_{i}^{1}\left(x^{1}, y^{1}\right)}{x_{n}^{1}\left(w^{1}, y^{1}\right)}}{\frac{x_{n}^{0} / D_{i}^{0}\left(x^{0}, y^{0}\right)}{x_{n}^{0}\left(w^{0}, y^{0}\right)}}\right)^{\phi_{n}^{01}} \times \prod_{n=1}^{N}\left(\frac{x_{n}^{1}\left(w^{1}, y^{1}\right)}{x_{n}^{0}\left(w^{0}, y^{0}\right)}\right)^{\phi_{n}^{01}} .
\end{aligned}
$$

The first factor in expression (23) is the technical efficiency effect, and the second factor is the allocative efficiency effect. The joint effect is given by the first factor in expression (22). This should also not be confused with cost efficiency change. The well-known, multiplicative, measure of cost efficiency at period $t$ is $C^{t}\left(w^{t}, y^{t}\right) / w^{t} \cdot x^{t}$, which is less than or equal to 1 , a larger magnitude indicating more efficiency. Cost efficiency change, going from period 0 to period 1 , is measured by $\left(C^{1}\left(w^{1}, y^{1}\right) / w^{1}\right.$. $\left.x^{1}\right) /\left(C^{0}\left(w^{0}, y^{0}\right) / w^{0} \cdot x^{0}\right){ }^{6}$ Using the cost function definition, this can be rewritten as

$\frac{\sum_{n=1}^{N} s_{n}^{1}\left(x_{n}^{1}\left(w^{1}, y^{1}\right) / x_{n}^{1}\right)}{\sum_{n=1}^{N} s_{n}^{0}\left(x_{n}^{0}\left(w^{0}, y^{0}\right) / x_{n}^{0}\right)}$.

\footnotetext{
${ }^{5}$ For any two positive real numbers $a$ and $b$, their logarithmic mean is defined by $L M(a, b) \equiv(a-b) / \ln (a / b)$ when $a \neq b$, and $L M(a, a) \equiv a$. It has the following properties: (1) $\min (a, b) \leq L M(a, b) \leq \max (a, b) ;(2) L M(a, b)$ is continuous; (3) $\operatorname{LM}(\lambda a, \lambda b)=\lambda \operatorname{LM}(a, b)(\lambda>0)$; (4) $\operatorname{LM}(a, b)=\operatorname{LM}(b, a)$; (5) $(a b)^{1 / 2} \leq \operatorname{LM}(a, b) \leq$ $(a+b) / 2$; $(6) L M(a, 1)$ is concave. More details in Balk $(2008,134-136)$.

${ }^{6}$ Diewert and Fox (2018) defined unit cost efficiency change as cost efficiency change divided by an output quantity index.
} 
This is not only a kind of inverse of the joint technical and allocative effect in expression (22), but also includes the full effect of price level change between periods 0 and 1 .

The third factor in expression (23) can be decomposed further as

$\prod_{n=1}^{N}\left(\frac{x_{n}^{1}\left(w^{1}, y^{1}\right)}{x_{n}^{0}\left(w^{0}, y^{0}\right)}\right)^{\phi_{n}^{01}}=\prod_{n=1}^{N}\left(\frac{x_{n}^{1}\left(w^{1}, y^{1}\right)}{x_{n}^{0}\left(w^{1}, y^{1}\right)} \frac{x_{n}^{1}\left(w^{0}, y^{0}\right)}{x_{n}^{0}\left(w^{0}, y^{0}\right)}\right)^{\phi_{n}^{01} / 2} \times$

$\prod_{n=1}^{N}\left(\frac{x_{n}^{1}\left(w^{1}, y^{1}\right)}{x_{n}^{1}\left(w^{1}, y^{0}\right)} \frac{x_{n}^{1}\left(w^{0}, y^{1}\right)}{x_{n}^{1}\left(w^{0}, y^{0}\right)} \frac{x_{n}^{0}\left(w^{1}, y^{1}\right)}{x_{n}^{0}\left(w^{1}, y^{0}\right)} \frac{x_{n}^{0}\left(w^{0}, y^{1}\right)}{x_{n}^{0}\left(w^{0}, y^{0}\right)}\right)^{\phi_{n}^{01} / 4} \times$

$\prod_{n=1}^{N}\left(\frac{x_{n}^{1}\left(w^{1}, y^{1}\right)}{x_{n}^{1}\left(w^{0}, y^{1}\right)} \frac{x_{n}^{1}\left(w^{1}, y^{0}\right)}{x_{n}^{1}\left(w^{0}, y^{0}\right)} \frac{x_{n}^{0}\left(w^{1}, y^{1}\right)}{x_{n}^{0}\left(w^{0}, y^{1}\right)} \frac{x_{n}^{0}\left(w^{1}, y^{0}\right)}{x_{n}^{0}\left(w^{0}, y^{0}\right)}\right)^{\phi_{n}^{01} / 4}$

which gives, respectively, the technological change, activity, and input price structure effect.

It is interesting to compare the decomposition provided by expressions (23) and (25)-(27) with an alternative, developed by Diewert (2014):

$\frac{w^{1} \cdot x^{1}}{w^{0} \cdot x^{0}}=\left(\frac{C^{0}\left(w^{1}, y^{0}\right)}{C^{0}\left(w^{0}, y^{0}\right)} \frac{C^{1}\left(w^{1}, y^{1}\right)}{C^{1}\left(w^{0}, y^{1}\right)}\right)^{1 / 2} \times$

$\left(\frac{C^{1}\left(w^{1}, y^{1}\right) / w^{1} \cdot x^{1}}{C^{0}\left(w^{0}, y^{0}\right) / w^{0} \cdot x^{0}}\right)^{-1} \times$

$\left(\frac{C^{0}\left(w^{1}, y^{0}\right)}{C^{1}\left(w^{1}, y^{0}\right)} \frac{C^{0}\left(w^{0}, y^{1}\right)}{C^{1}\left(w^{0}, y^{1}\right)}\right)^{-1 / 2} \times$

$\left(\frac{C^{0}\left(w^{0}, y^{1}\right)}{C^{0}\left(w^{0}, y^{0}\right)} \frac{C^{1}\left(w^{1}, y^{1}\right)}{C^{1}\left(w^{1}, y^{0}\right)}\right)^{1 / 2}$.

There are only four factors distinguished. The first factor on the right-hand side, expression (28), is a Fisher-type cost-functionbased input price index ${ }^{7}$, comparable with the empirical SatoVartia input price index in expression (19). The second factor, expression (29), measures inverse cost efficiency change, which can be compared with the joint technical and allocative effects in expression (22). The third factor, expression (30), measures inverse technological change ${ }^{8}$, and must be compared with expression (25). Notice that Diewert's measure of technological change exhibits some asymmetry in the sense that it conditions on $\left(w^{1}, y^{0}\right)$ and $\left(w^{0}, y^{1}\right)$ instead of $\left(w^{1}, y^{1}\right)$ and $\left(w^{0}, y^{0}\right)$. The fourth factor, expression (31), is a Fisher-type cost-function-based output quantity index, comparable with the activity effect in expression (26). ${ }^{9}$ Notice also that the cost ratio, $w^{1} \cdot x^{1} / w^{0} \cdot x^{0}$, occurs on both sides of the equality sign, which makes the right-hand side less attractive as a decomposition of the left-hand side.

Grifell-Tatjé and Lovell $(2015,283)$ proposed a slightly different decomposition, namely

$\frac{w^{1} \cdot x^{1}}{w^{0} \cdot x^{0}}=\left(\frac{C^{0}\left(w^{1}, y^{0}\right)}{C^{0}\left(w^{0}, y^{0}\right)} \frac{C^{1}\left(w^{1}, y^{1}\right)}{C^{1}\left(w^{0}, y^{1}\right)}\right)^{1 / 2} \times$

$\left(\frac{C^{1}\left(w^{1}, y^{1}\right) / w^{1} \cdot x^{1}}{C^{0}\left(w^{0}, y^{0}\right) / w^{0} \cdot x^{0}}\right)^{-1} \times$

$\left(\frac{C^{0}\left(w^{0}, y^{0}\right)}{C^{1}\left(w^{0}, y^{0}\right)} \frac{C^{0}\left(w^{1}, y^{1}\right)}{C^{1}\left(w^{1}, y^{1}\right)}\right)^{-1 / 2} \times$

\footnotetext{
7 The properties of such an index are discussed in Balk (1998, 33-35).

8 Dual input based technological change, going from period 0 to period 1 , is generically defined by $C^{0}(w, y) / C^{1}(w, y)$ (Balk, 1998, 58).

${ }^{9}$ This output quantity index is not linearly homogeneous, unless the technologies exhibit constant returns to scale.
}

$\left(\frac{C^{0}\left(w^{1}, y^{1}\right)}{C^{0}\left(w^{1}, y^{0}\right)} \frac{C^{1}\left(w^{0}, y^{1}\right)}{C^{1}\left(w^{0}, y^{0}\right)}\right)^{1 / 2}$,

in which the asymmetry has been moved from the technological change component to the output quantity index. It is straightforward to derive structurally identical decompositions for the difference $w^{1} \cdot x^{1}-w^{0} \cdot x^{0}$ Grifell-Tatjé and Lovell (2015, 282-288).

If $y^{0}=y^{1}$, then the fourth factor in these two decompositions vanishes, and we obtain the multiplicative variant of the decomposition proposed by Grifell-Tatjé and Lovell (2003). Notice that in this particular case all the factors are symmetric. ${ }^{10}$

\section{More decompositions}

In Section 3 we considered an additive decomposition of the cost variation $w^{1} \cdot x^{1}-w^{0} \cdot x^{0}$, and in Section 4 we considered a structurally similar, multiplicative decomposition of $w^{1} \cdot x^{1} / w^{0} \cdot x^{0}$. The logarithmic mean can be used to devise two more decompositions, relating the additive and multiplicative approach. The first starts with

$w^{1} \cdot x^{1}-w^{0} \cdot x^{0}=L M\left(w^{0} \cdot x^{0}, w^{1} \cdot x^{1}\right) \ln \left(\frac{w^{1} \cdot x^{1}}{w^{0} \cdot x^{0}}\right)$

and proceeds by applying expression (19) and subsequent expressions to the right-hand side of expression (36). This leads to an alternative additive decomposition.

The second starts with the reciprocal version of expression (36),

$\frac{w^{1} \cdot x^{1}}{w^{0} \cdot x^{0}}=\exp \left\{\frac{w^{1} \cdot x^{1}-w^{0} \cdot x^{0}}{L M\left(w^{0} \cdot x^{0}, w^{1} \cdot x^{1}\right)}\right\}$

and proceeds by applying expression (1) and subsequent expressions to the numerator on the right-hand side of expression (37). This leads to an alternative multiplicative decomposition.

But this is still not the end of the story. An alternative to expression (19) is

$\frac{w^{1} \cdot x^{1}}{w^{0} \cdot x^{0}}=\prod_{n=1}^{N}\left(w_{n}^{1} / w_{n}^{0}\right)^{\psi_{n}^{01}} \times \prod_{n=1}^{N}\left(x_{n}^{1} / x_{n}^{0}\right)^{\psi_{n}^{01}}$,

where

$\psi_{n}^{01} \equiv \frac{L M\left(w_{n}^{0} x_{n}^{0}, w_{n}^{1} x_{n}^{1}\right)}{L M\left(w^{0} \cdot x^{0}, w^{1} \cdot x^{1}\right)}(n=1, \ldots, N)$.

This is a decomposition in terms of Montgomery-Vartia price and quantity indices (see Balk, 2008 for definitions and properties). The noteworthy feature here is that the weights $\psi_{n}^{01}$ do not add up to 1 . In all empirical applications we have seen, however, the discrepancy appears to be negligible.

We can now develop two additional decompositions. The first is multiplicative. Expression (38) can be decomposed in the same way as expression (19) was decomposed. All we have to do is to replace the weights $\phi_{n}^{01}$ by $\psi_{n}^{01}$. Notice that the technical efficiency effect then appears as

$\left(\frac{D_{i}^{1}\left(x^{1}, y^{1}\right)}{D_{i}^{0}\left(x^{0}, y^{0}\right)}\right)^{\sum_{n=1}^{N} \psi_{n}^{01}}$.

The second is additive. Combining expression (36) with expression (38) gives

\footnotetext{
10 The context in Grifell-Tatjé and Lovell (2003) is not longitudinal measurement but benchmarking. To be precise, $t=1$ represents the actual situation of a firm as perceived by its managers, and $t=0$ the benchmark situation as designed by consultants.
} 
Table 1

Descriptive statistics, 2006-2010.

\begin{tabular}{|c|c|c|c|c|c|c|c|c|}
\hline & \multicolumn{4}{|l|}{2006} & \multicolumn{4}{|l|}{2010} \\
\hline & Average & Max. & Min. & St. Dev. & Average & Max. & Min. & St. Dev. \\
\hline$x_{1}$ & 628,856 & $2,133,665$ & 26,162 & 578,979 & 795,536 & $3,171,493$ & 25,019 & 768,008 \\
\hline$x_{2}$ & 3781 & 8463 & 203 & 2463 & 3826 & 9538 & 202 & 2729 \\
\hline$x_{3}$ & 14,623 & 74,448 & 494 & 15,971 & 13,393 & 76,576 & 505 & 15,185 \\
\hline$w_{1}$ & 0.0203 & 0.0776 & 0.0107 & 0.0124 & 0.0064 & 0.0186 & 0.0025 & 0.0026 \\
\hline$w_{2}$ & 1.1538 & 2.6926 & 0.6875 & 0.4394 & 1.2586 & 2.2963 & 0.7170 & 0.3963 \\
\hline$w_{3}$ & 0.3106 & 0.8325 & 0.0631 & 0.1750 & 0.3171 & 0.7625 & 0.0725 & 0.1697 \\
\hline$y_{1}$ & 111,098 & 352,976 & 2354 & 108,651 & 196,808 & 904,580 & 1681 & 215,063 \\
\hline$y_{2}$ & 506,372 & $1,734,526$ & 49,780 & 468,063 & 609,489 & $2,091,100$ & 66,947 & 582,854 \\
\hline
\end{tabular}

Table 2

Spearman correlations between additive and multiplicative effects.

\begin{tabular}{llllll}
\hline & $T E_{S V}$ & $A E_{S V}$ & $T C_{S V}$ & $A c t . E_{S V}$ & $I P S_{S V}$ \\
\hline$T E_{A}$ & $0.8583^{* *}$ & -0.1637 & 0.0069 & $-0.4168^{*}$ & -0.0568 \\
$A E_{A}$ & $-0.4715^{* *}$ & $0.7765^{* *}$ & 0.3179 & -0.0813 & 0.1589 \\
$T C_{A}$ & 0.3012 & 0.1344 & $0.5903^{* *}$ & $-0.6222^{* *}$ & -0.2195 \\
$A c t . E_{A}$ & $-0.4445^{*}$ & -0.1772 & -0.1464 & $0.8073^{*}$ & -0.0758 \\
$I P S_{A}$ & 0.0327 & 0.3176 & 0.0400 & -0.2542 & 0.1193 \\
\hline
\end{tabular}

Note: ${ }^{*} p<0.01 ;{ }^{* *} p<0.05$.

$$
\begin{aligned}
w^{1} \cdot x^{1}-w^{0} \cdot x^{0}= & \sum_{n=1}^{N} \operatorname{LM}\left(w_{n}^{0} x_{n}^{0}, w_{n}^{1} x_{n}^{1}\right) \ln \left(w_{n}^{1} / w_{n}^{0}\right) \\
& +\sum_{n=1}^{N} \operatorname{LM}\left(w_{n}^{0} x_{n}^{0}, w_{n}^{1} x_{n}^{1}\right) \ln \left(x_{n}^{1} / x_{n}^{0}\right)
\end{aligned}
$$

The second factor on the right-hand side, being the input quantity effect, can then be decomposed into the by now well-known five components.

\section{An application: Taiwanese banking industry}

\subsection{DEA approach and data}

Any application of the decompositions developed in the previous sections presupposes knowledge of the period $t$ technology. Given data on a number of firms, which are supposed to share the same technology, this technology can be approximated by way of non-parametric Data Envelopment Analysis methods. In particular, given data $\left(x^{k t}, y^{k t}\right)$ for $k=1, \ldots, K^{t}$ and $t=0,1$, any input distance function value can be computed by solving the following linear programming problem

$$
\begin{aligned}
1 / D_{i}^{t}(x, y)= & \min _{z, \lambda} \lambda \text { subject to } \\
& \sum_{k^{\prime}=1}^{K^{t}} z_{k^{\prime}} x^{k^{\prime} t} \leq \lambda x, y \leq \sum_{k^{\prime}=1}^{K^{t}} z_{k^{\prime}} y^{k^{\prime} t}, \\
& z_{k^{\prime}} \geq 0\left(k^{\prime}=1, \ldots, K^{t}\right),\left[\sum_{k^{\prime}=1}^{K^{t}} z_{k^{\prime}}=1\right],
\end{aligned}
$$

and any cost minimizing input quantity vector $x^{t}(w, y)$ can be obtained as the solution to the following linear programming problem

$$
\begin{aligned}
x^{t}(w, y)= & \arg \min _{z, x} w \cdot x \text { subject to } \\
& \sum_{k^{\prime}=1}^{K^{t}} z_{k^{\prime}} x^{k^{\prime} t} \leq x, y \leq \sum_{k^{\prime}=1}^{K^{t}} z_{k^{\prime}} y^{k^{\prime} t}, \\
& z_{k^{\prime}} \geq 0\left(k^{\prime}=1, \ldots, K^{t}\right),\left[\sum_{k^{\prime}=1}^{K^{t}} z_{k^{\prime}}=1\right] .
\end{aligned}
$$

The restriction between brackets in expressions (41) and (42) must be deleted in the case of imposing global constant returns to scale. However, given the different sizes of the production units in the example below we do not impose this. Distance function as well as cost function values can be computed for firm data contemporaneous with period $t$ or not. ${ }^{11}$

Our example uses data of a balanced panel of 31 Taiwanese banks over the period 2006-2010. Regarding the technology and interrelations between inputs and outputs, the variables reflect the intermediation approach suggested by Sealey and Lindley (1977), in which financial institutions, through labour and capital, collect deposits from savers to produce loans and other earning assets for borrowers. The three inputs are financial funds $\left(x_{1}\right)$, labour $\left(x_{2}\right)$, and physical capital $\left(x_{3}\right)$. The output vector includes financial investments $\left(y_{1}\right)$ and loans $\left(y_{2}\right)$. Table 1 presents descriptive statistics for quantities and prices in 2006 and 2010. A complete discussion of the statistical sources and variable specifications can be found in Juo, Fu, Yu, and Lin (2015). Firm-specific prices are calculated as unit values, that is, costs divided by quantities. What immediately catches the eye is that all the variables exhibit in both years huge dispersion, and that relative prices have changed considerably from 2006 to $2010 .^{12}$

\subsection{Additive decompositions}

Table 3 presents the additive decomposition of cost variation between 2006 and 2010: $\Delta C_{A}^{06,10}=w^{10} \cdot x^{10}-w^{06} \cdot x^{06}$. Cost in the Taiwanese banking industry has generally decreased for all banks, with an (arithmetic) average reduction of 6459 million TWD, led by Bank \#2 with -26,957 million TWD. The Bennet decomposition, expression (1), shows that the main driver of the cost reduction is an input price decrease to the tune of -8406 million TWD on average (see the column headed $I P I_{B}$ ). Unsurprisingly, such a decrease of input prices results in an increase of input quantities, as shown by the positive value of the Bennet input quantity indicator $\left(I Q I_{B}\right)$, whose average amounts to 1946 million TWD. It is possible to learn about the sources of the cost reduction by resorting to the asymmetric decomposition proposed by Grifell-Tatjé and Lovell (2000) (GL), expressions (2)-(5), and the symmetric one introduced here (A), expressions (2), (3), (6)-(8).

As many as nine banks are technically efficient in both periods, and therefore their technical efficiency change is zero, $T E_{A}=0$. Of these, four are also allocatively efficient, $A E_{A}=0$, implying that they minimize costs at their production scale (output level), and therefore cannot perform better from an efficiency perspective.

\footnotetext{
${ }^{11}$ For the linear programming problems in this paper the MATLAB toolbox developed by Álvarez, Barbero, and Zofío (2019) has been used.

12 We are grateful to Juo et al. for sharing the data. We emphasize that we are using these data only as an example, and not for revealing any hitherto unknown feature of the Taiwanese banking sector or individual banks. The same data set has been used to illustrate the decompositions of total factor productivity change using quantities-only and price-based indices by Balk and Zofío (2018).
} 
Table 3

Decomposition of cost variation. Additive approach: Bennet, Grifell-Tatjé and Lovell (2000), and this paper.

\begin{tabular}{|c|c|c|c|c|c|c|c|c|c|c|c|c|}
\hline \multirow[b]{2}{*}{ Bank } & \multirow[b]{2}{*}{$C^{06}$} & \multirow[b]{2}{*}{$C^{10}$} & \multirow[b]{2}{*}{$\Delta C_{A}^{0610}$} & \multicolumn{2}{|c|}{ Bennet (1) } & \multirow[b]{2}{*}{$\begin{array}{l}\text { Technical } \\
\text { Efficiency } \\
\text { Effect (2) } \\
T E_{A}\end{array}$} & \multirow[b]{2}{*}{$\begin{array}{l}\text { Allocative } \\
\text { Efficiency } \\
\text { Effect (3) } \\
A E_{A}\end{array}$} & \multicolumn{2}{|c|}{ Grifell-Tatjé and Lovell (2000) } & \multicolumn{3}{|l|}{ This paper } \\
\hline & & & & $I P I_{B}$ & $I Q I_{B}$ & & & $\begin{array}{l}\text { Technological } \\
\text { Change } \\
\text { Effect (4) } \\
T C_{G L}\end{array}$ & $\begin{array}{l}\text { Activity } \\
\text { Effect } \\
(5) \\
\text { Act. } E_{G L}\end{array}$ & $\begin{array}{l}\text { Technological } \\
\text { Change } \\
\text { Effect (6) } \\
T C_{A}\end{array}$ & $\begin{array}{l}\text { Activity } \\
\text { Effect } \\
(7) \\
\text { Act. } E_{A}\end{array}$ & $\begin{array}{l}\text { Input } \\
\text { Price } \\
\text { Structure (8) } \\
I P S_{A}\end{array}$ \\
\hline 1 & 2539 & 936 & -1603 & -1549 & -54 & 0 & 0 & 95 & -148 & -600 & 546 & 0 \\
\hline 2 & 68,347 & 41,390 & $-26,957$ & $-45,846$ & 18,889 & 0 & 0 & $-13,579$ & 32,469 & 10,309 & 8580 & 1 \\
\hline 3 & 23,676 & 19,703 & -3973 & -6714 & 2741 & -6793 & 290 & -686 & 9931 & -6891 & 16,138 & -3 \\
\hline 4 & 3648 & 2861 & -787 & -1438 & 651 & -122 & -10 & -188 & 970 & -312 & 1098 & -3 \\
\hline 5 & 42,069 & 25,038 & $-17,031$ & $-17,885$ & 854 & 0 & -1989 & -3574 & 6416 & -6835 & 9677 & 1 \\
\hline 6 & 48,987 & 34,011 & $-14,976$ & $-19,296$ & 4320 & 0 & 695 & -4238 & 7864 & 4612 & -987 & 0 \\
\hline 7 & 35,956 & 22,112 & $-13,844$ & $-15,943$ & 099 & 0 & -628 & -8063 & 10,790 & -2694 & 5251 & 170 \\
\hline 8 & 35,100 & 22,874 & $-12,226$ & $-15,587$ & 3361 & -4332 & 424 & -510 & 7778 & -1180 & 8391 & 58 \\
\hline 9 & 30,582 & 18,939 & $-11,643$ & $-14,547$ & 2904 & -1032 & 1400 & -823 & 3359 & 72 & 2545 & -80 \\
\hline 10 & 50,757 & 28,625 & $-22,132$ & $-30,239$ & 8107 & 0 & 0 & 555 & 7553 & -2640 & 10,756 & -8 \\
\hline 11 & 26,936 & 21,454 & $-5,482$ & $-12,421$ & 6940 & 2536 & 347 & -377 & 4434 & -369 & 4427 & 0 \\
\hline 12 & 10,804 & 7047 & -3757 & -5985 & 2228 & -2207 & 622 & 439 & 3374 & -2837 & 6543 & 107 \\
\hline 13 & 11,955 & 6996 & -4959 & -4377 & -582 & 790 & -512 & -197 & -662 & -324 & -537 & 2 \\
\hline 14 & 9287 & 7205 & -2082 & -3232 & 1149 & 0 & -2243 & -712 & 4104 & $-12,649$ & 16,108 & -67 \\
\hline 15 & 15,971 & 14,379 & -1592 & -7314 & 5722 & -443 & -566 & -16 & 6746 & -8523 & 15,257 & -4 \\
\hline 16 & 10,608 & 4748 & -5860 & -2196 & -3664 & -130 & -1638 & -507 & -1390 & -361 & -1535 & 0 \\
\hline 17 & 25,499 & 15,888 & -9611 & -9294 & -317 & -1177 & 106 & -515 & 1269 & -1037 & 1790 & 2 \\
\hline 18 & 10,097 & 7423 & -2674 & -3705 & 1032 & 737 & -386 & -635 & 1315 & -394 & 1,079 & -4 \\
\hline 19 & 8285 & 3958 & -4327 & -2841 & -1486 & 743 & -795 & -407 & -1027 & -366 & -1073 & 5 \\
\hline 20 & 6228 & 4751 & -1477 & -1377 & -99 & -270 & 1265 & -374 & -719 & -412 & -700 & 19 \\
\hline 21 & 50,284 & 36,733 & $-13,551$ & $-16,813$ & 3262 & 0 & 9183 & $-19,355$ & 13,434 & $-10,895$ & 4974 & 0 \\
\hline 22 & 6615 & 3,910 & -2705 & -1915 & -789 & 308 & -532 & -171 & -395 & -270 & -300 & 4 \\
\hline 23 & 4922 & 2844 & -2078 & -1848 & -230 & 1161 & -330 & -371 & -690 & -372 & -689 & 0 \\
\hline 24 & 22,458 & 16,095 & -6363 & -8604 & 2241 & -974 & 60 & -336 & 3490 & -392 & 3547 & 0 \\
\hline 25 & 5969 & 4275 & -1694 & -2040 & 345 & -276 & -5 & -396 & 1,023 & -406 & 1033 & 0 \\
\hline 26 & 3429 & 1942 & -1487 & -2323 & 836 & 0 & 0 & 1,036 & -200 & 957 & -121 & 0 \\
\hline 27 & 2520 & 2063 & -457 & -480 & 24 & 340 & -146 & -298 & 128 & -344 & 174 & 0 \\
\hline 28 & 2761 & 2078 & -683 & -423 & -261 & -215 & 259 & -363 & 59 & -375 & 71 & 0 \\
\hline 29 & 2673 & 1631 & -1042 & -1885 & 843 & -245 & 734 & 198 & 156 & 193 & 161 & 0 \\
\hline 30 & 14,601 & 14,368 & -233 & -564 & 331 & -142 & -138 & -1529 & 2141 & -3455 & 4062 & 5 \\
\hline 31 & 10,208 & 7258 & -2950 & -1894 & -1056 & -595 & -1679 & -389 & 1607 & -398 & 1615 & 0 \\
\hline $\begin{array}{l}\text { Aritm. } \\
\text { Average }\end{array}$ & 19,477 & 13,017 & -6459 & -8406 & 1946 & -398 & 122 & -1816 & 4038 & -1587 & 3803 & 7 \\
\hline Median & 10,804 & 7258 & -3757 & -3705 & 843 & 0 & 0 & -389 & 1607 & -394 & 1615 & 0 \\
\hline Maximum & 68,347 & 41,390 & -233 & -423 & 18,889 & 2536 & 9183 & 1036 & 32,469 & 10,309 & 16,138 & 170 \\
\hline Minimum & 2520 & 936 & $-26,957$ & $-45,846$ & -3664 & -6793 & -2243 & $-19,355$ & -1390 & $-12,649$ & -1535 & -80 \\
\hline Std. Dev. & 17,780 & 11,462 & 6868 & 10,076 & 4000 & 1621 & 1879 & 4323 & 6580 & 4223 & 5239 & 42 \\
\hline
\end{tabular}

As for the remaining inefficient banks, most of them experience technical efficiency gains resulting in lower costs, $T E_{A}<0$. A remarkable example is Bank \#3, whose approach to the production frontier from 2006 to 2010 resulted in cost savings equal to 6793 million TWD. On the other hand, seven banks exhibit greater technical inefficiency, $T E_{A}>0$, but their associated cost increase never surpasses 1000 million TWD. The role played by allocative (in)efficiency is equally important in monetary terms. Allocative efficiency reflects the ability of production units to anticipate the change of input prices from base to comparison year, and thereby demand optimal input quantities, given their individual prices. Overall, the direction of allocative efficiency change is inconclusive: 11 banks experienced increasing cost, $A E_{A}>0$, and 15 decreasing cost, $A E_{A}<0$.

Technical and allocative efficiency components are common to both decompositions because they compare prices, quantities, and technologies of contemporaneous periods. However, the difference between the two decompositions emerges when mixed period evaluations are brought into the analysis. The effect of technological progress on cost reduction, as measured by the inner product of the mean price vector and expression (6), appears to be on average $T C_{A}=-1587$ million TWD. According to the GL measure, the inner product of the mean price vector and expression (4), the average magnitude appears to be $T C_{G L}=-1.816$ million TWD.
The compatibility of individual results is rather low, as indicated by the Spearman correlation, $\rho\left(T C_{G L}, T C_{A}\right)=0.2077$, which is statistically insignificant at the usual levels. The activity component (output quantity in- or decrease leads to cost in- or decrease, respectively) appears to be larger in the GL decomposition than in our symmetric decomposition, Act. $E_{G L}=4038$ million TWD but Act. $E_{A}=3803$ million TWD. In this case, however, the correlation is significantly positive, $\rho\left(\right.$ Act. $E_{G L}$, Act. $\left.E_{A}\right)=0.8145$. We also see that the shift in input price structure has a negligible effect on cost. Recall that the input price level effect is captured by $I P I_{B}$.

Actually, such differences between the two decompositions should be investigated on a case-by-case base. Consider for instance Bank \#2. As the input price structure effect here is negligible, the GL measure of technological change (TC) reduces to

$\frac{1}{2}\left(w^{0}+w^{1}\right) \cdot\left[x^{1}\left(w^{0}, y^{0}\right)-x^{0}\left(w^{0}, y^{0}\right)\right]=-13,579$,

which equals the 'right half of the symmetric measure

$\frac{1}{4}\left(w^{0}+w^{1}\right) \cdot\left[x^{1}\left(w^{1}, y^{1}\right)-x^{0}\left(w^{1}, y^{1}\right)+x^{1}\left(w^{0}, y^{0}\right)-x^{0}\left(w^{0}, y^{0}\right)\right]$
$=10,309$.

We conclude that the 'left half' is equal to

$\frac{1}{2}\left(w^{0}+w^{1}\right) \cdot\left[x^{1}\left(w^{1}, y^{1}\right)-x^{0}\left(w^{1}, y^{1}\right)\right]=34,197$. 
Table 4

Decomposition of cost variation. Multiplicative approach: Sato-Vartia and this paper.

\begin{tabular}{|c|c|c|c|c|c|c|c|c|c|c|}
\hline \multirow[b]{2}{*}{ Bank } & \multirow[b]{2}{*}{$C^{06}$} & \multirow[b]{2}{*}{$C^{10}$} & \multirow[b]{2}{*}{$\Delta C_{M}^{0610}$} & \multicolumn{2}{|c|}{ Sato-Vartia } & \multicolumn{5}{|l|}{ This paper } \\
\hline & & & & $I P I_{S V}$ & $I Q I_{S V}$ & $\begin{array}{l}\text { Technical } \\
\text { Efficiency } \\
\text { Effect } \\
(23) \\
T E_{S V} \\
\end{array}$ & $\begin{array}{l}\text { Allocative } \\
\text { Efficiency } \\
\text { Effect } \\
(23) \\
A E_{S V}\end{array}$ & $\begin{array}{l}\text { Technological } \\
\text { Change } \\
\text { Effect } \\
(25) \\
T C_{S V}\end{array}$ & $\begin{array}{l}\text { Activity } \\
\text { Effect } \\
(26) \\
\text { Act. } E_{S V}\end{array}$ & $\begin{array}{l}\text { Input } \\
\text { Price } \\
\text { Structure } \\
(27) \\
I P S_{S V}\end{array}$ \\
\hline 1 & 2539 & 936 & 0.3686 & 0.3793 & 0.9718 & 1.0000 & 1.0000 & 0.7809 & 1.2445 & 1.0000 \\
\hline 2 & 68,347 & 41,390 & 0.6056 & 0.4440 & 1.3640 & 1.0000 & 1.0000 & 1.1936 & 1.1431 & 0.9998 \\
\hline 3 & 23,676 & 19,703 & 0.8322 & 0.7433 & 1.1196 & 0.6776 & 0.9484 & 0.7705 & 2.2637 & 0.9988 \\
\hline 4 & 3648 & 2861 & 0.7842 & 0.6593 & 1.1894 & 0.8263 & 0.9695 & 0.8503 & 1.7518 & 0.9967 \\
\hline 5 & 42,069 & 25,038 & 0.5952 & 0.5851 & 1.0171 & 1.0000 & 0.9514 & 0.8191 & 1.3058 & 0.9995 \\
\hline 6 & 48,987 & 34,011 & 0.6943 & 0.6289 & 1.1040 & 1.0000 & 1.0382 & 1.1128 & 0.9556 & 1.0000 \\
\hline 7 & 35,956 & 22,112 & 0.6150 & 0.5765 & 1.0667 & 1.0000 & 1.0113 & 0.8540 & 1.2378 & 0.9978 \\
\hline 8 & 35,100 & 22,874 & 0.6517 & 0.5854 & 1.1131 & 0.8293 & 1.0092 & 0.9232 & 1.4395 & 1.0006 \\
\hline 9 & 30,582 & 18,939 & 0.6193 & 0.5574 & 1.1109 & 0.9458 & 1.1132 & 0.9562 & 1.1309 & 0.9757 \\
\hline 10 & 50,757 & 28,625 & 0.5640 & 0.4793 & 1.1765 & 1.0000 & 1.0000 & 0.9292 & 1.2680 & 0.9986 \\
\hline 11 & 26,936 & 21,454 & 0.7965 & 0.6116 & 1.3023 & 1.0334 & 1.0034 & 0.9371 & 1.3403 & 1.0000 \\
\hline 12 & 10,804 & 7047 & 0.6523 & 0.5229 & 1.2473 & 0.6685 & 1.0780 & 0.7650 & 2.2555 & 1.0032 \\
\hline 13 & 11,955 & 6996 & 0.5852 & 0.6240 & 0.9378 & 1.2219 & 1.0111 & 0.8669 & 0.8757 & 0.9999 \\
\hline 14 & 9287 & 7205 & 0.7758 & 0.6791 & 1.1424 & 1.0000 & 0.6680 & 0.4993 & 3.4171 & 1.0023 \\
\hline 15 & 15,971 & 14,379 & 0.9003 & 0.6345 & 1.4189 & 0.8794 & 0.9005 & 0.6659 & 2.6922 & 0.9994 \\
\hline 16 & 10,608 & 4748 & 0.4476 & 0.7398 & 0.6050 & 2.2748 & 0.8670 & 0.7931 & 0.3868 & 1.0000 \\
\hline 17 & 25,499 & 15,888 & 0.6231 & 0.6366 & 0.9787 & 0.9354 & 1.0515 & 0.8505 & 1.1756 & 0.9952 \\
\hline 18 & 10,097 & 7423 & 0.7352 & 0.6567 & 1.1195 & 1.0819 & 0.9099 & 0.9247 & 1.2282 & 1.0014 \\
\hline 19 & 8285 & 3958 & 0.4777 & 0.6163 & 0.7752 & 1.4653 & 0.9527 & 0.8319 & 0.6689 & 0.9980 \\
\hline 20 & 6228 & 4751 & 0.7629 & 0.7753 & 0.9840 & 0.9455 & 1.4192 & 0.8810 & 0.8250 & 1.0088 \\
\hline 21 & 50,284 & 36,733 & 0.7305 & 0.6782 & 1.0771 & 1.0000 & 1.3149 & 0.6708 & 1.2213 & 1.0000 \\
\hline 22 & 6615 & 3910 & 0.5911 & 0.6900 & 0.8566 & 1.1834 & 0.9514 & 0.8628 & 0.8887 & 0.9923 \\
\hline 23 & 4922 & 2844 & 0.5778 & 0.6136 & 0.9416 & 1.8763 & 1.0272 & 0.7634 & 0.6400 & 1.0000 \\
\hline 24 & 22,458 & 16,095 & 0.7167 & 0.6444 & 1.1121 & 0.9419 & 1.0043 & 0.9450 & 1.2441 & 1.0000 \\
\hline 25 & 5969 & 4275 & 0.7162 & 0.6786 & 1.0554 & 0.9000 & 0.9885 & 0.8514 & 1.3932 & 1.0000 \\
\hline 26 & 3429 & 1942 & 0.5664 & 0.4749 & 1.1927 & 1.0000 & 1.0000 & 1.2348 & 0.9659 & 1.0000 \\
\hline 27 & 2520 & 2063 & 0.8188 & 0.8144 & 1.0054 & 1.4030 & 0.8826 & 0.6631 & 1.2244 & 1.0000 \\
\hline 28 & 2,761 & 2,078 & 0.7525 & 0.8359 & 0.9003 & 0.9358 & 1.4001 & 0.6305 & 1.0898 & 1.0000 \\
\hline 29 & 2673 & 1631 & 0.6101 & 0.4322 & 1.4118 & 0.8749 & 1.2592 & 1.1427 & 1.1214 & 1.0000 \\
\hline 30 & 14,601 & 14,368 & 0.9841 & 0.9637 & 1.0211 & 0.9864 & 0.9892 & 0.7706 & 1.3560 & 1.0015 \\
\hline 31 & 10,208 & 7258 & 0.7110 & 0.8099 & 0.8779 & 0.9589 & 0.7166 & 0.8721 & 1.4651 & 1.0000 \\
\hline Arithm. Average & 19,477 & 13,017 & 0.6730 & 0.6378 & 1.0709 & 1.0595 & 1.0141 & 0.8585 & 1.3295 & 0.9990 \\
\hline Median & 10,804 & 7258 & 0.6523 & 0.6345 & 1.0771 & 1.0000 & 1.0000 & 0.8514 & 1.2282 & 1.0000 \\
\hline Maximum & 68,347 & 41,390 & 0.9841 & 0.9637 & 1.4189 & 2.2748 & 1.4192 & 1.2348 & 3.4171 & 1.0088 \\
\hline Minimum & 2520 & 936 & 0.3686 & 0.3793 & 0.6050 & 0.6685 & 0.6680 & 0.4993 & 0.3868 & 0.9757 \\
\hline Std. Dev. & 17,780 & 11,462 & 0.1308 & 0.1271 & 0.1780 & 0.3207 & 0.1603 & 0.1607 & 0.6095 & 0.0050 \\
\hline
\end{tabular}

Thus, even when the input price structure plays a negligible role, it appears that the magnitude of TC heavily depends on the value of the conditioning variable output quantity. Put otherwise, there must be locally great differences in the magnitude of TC. In the case of Bank \#2 the activity effect is indeed rather large.

In general, although technological change contributes significantly to cost decrease, the effect of output quantity growth more than compensates this gain, ultimately resulting in cost increase. This explains the positive value of the Bennet quantity index $\left(I Q I_{B}\right)$, and suggests the existence of scale inefficiencies in the Taiwanese banking industry, as confirmed by Balk and Zofío (2018, Section 4). We therefore conclude that, on average, the main drivers of cost decrease are the general decline of input prices, technological progress, and a mild gain in technical efficiency. On the other hand, allocative inefficiency and scale effects work against cost reduction.

\subsection{Multiplicative decompositions}

Table 4 reports the results of the Sato-Vartia (SV) based multiplicative decomposition of cost variation from 2006 to 2010, $\Delta C_{M}^{06,10}=w^{10} \cdot x^{10} / w^{06} \cdot x^{06}$. As cost in the Taiwanese banking industry has decreased, the ratio is smaller than one for all banks, with an average reduction of $(13,017 / 19,477-1) \times 100=-33.2 \%$. The cost reduction is now led by Bank \#1 with $-63.1 \%$. The SV decomposition, expression (19), shows that most of this reduction is due to decreased prices since the SV input price index $I P I_{S V}$ is equal to 0.6378 on average $(-36.2 \%)$. As a result of this price decrease input quantities on average increased by $7.1 \%\left(I Q I_{S V}=1.0709\right)$. The results of both indices are consistent with the findings reported in the previous subsection, which is not surprising as they constitute the multiplicative counterpart of the additive Bennet indicators.

Following the decomposition set out in expressions (23)-(27), we can study the sources of cost reduction. Since the quantity index increases over time on average, given the results of the previous subsection one expects index numbers greater than one except for technological change. This is the case for the technical efficiency effect, showing an average increase of 5.95\%, $T E_{S V}=1.0595$. This is opposite to the average efficiency effect in the additive decomposition, $T E_{A}$, which contributes to the cost reduction with 398 million TWD. The allocative efficiency effect $A E_{S V}$ is also positive, signaling a worsening performance to the tune of $1.41 \%$, which is consistent with the average cost increase of 122 million TWD reported in Table 3, column $A E_{A}$.

Thus multiplicative and additive decompositions may lead to different conclusions regarding the drivers of cost change; put otherwise, a consistent numerical relationship between the components of both decompositions does not exist. Only in the case of technical and allocative efficiency, the zero values in the additive approach correspond with index numbers equal to one in the multiplicative approach. This is the case of the nine technically efficient banks, of which four are also allocatively efficient, and 
Table 5

Decomposition of cost variation. Multiplicative approach: Diewert (2014), Grifell-Tatjé and Lovell (2015).

\begin{tabular}{|c|c|c|c|c|c|c|c|c|c|}
\hline \multirow[b]{2}{*}{ Bank } & \multirow[b]{2}{*}{$C^{06}$} & \multirow[b]{2}{*}{$C^{10}$} & \multirow[b]{2}{*}{$\Delta C_{M}^{0610}$} & \multicolumn{4}{|c|}{ Diewert (2014) } & \multicolumn{2}{|c|}{ Grifell-Tatjé and Lovell (2015) } \\
\hline & & & & $\begin{array}{l}\text { Input } \\
\text { Price } \\
\text { Index } \\
(28) \\
I P I_{D}\end{array}$ & $\begin{array}{l}\text { Cost } \\
\text { Efficiency } \\
\text { Change } \\
(29) \\
C E_{D}\end{array}$ & $\begin{array}{l}\text { Technological } \\
\text { Change } \\
(30) \\
T C_{D}\end{array}$ & $\begin{array}{l}\text { Output } \\
\text { Quantity } \\
\text { Index } \\
(31) \\
O Q I_{D}\end{array}$ & $\begin{array}{l}\text { Technological } \\
\text { Change } \\
(34) \\
T_{G L}\end{array}$ & $\begin{array}{l}\text { Output } \\
\text { Quantity } \\
\text { Index } \\
(35) \\
O Q I_{G L}\end{array}$ \\
\hline 1 & 2539 & 936 & 0.3686 & 0.3792 & 1.0000 & 0.7682 & 1.2656 & 0.7920 & 1.2276 \\
\hline 2 & 68,347 & 41,390 & 0.6056 & 0.4456 & 1.0000 & 1.1907 & 1.1413 & 1.1705 & 1.1610 \\
\hline 3 & 23,676 & 19,703 & 0.8322 & 0.7245 & 0.6625 & 0.7668 & 2.2610 & 0.7486 & 2.3160 \\
\hline 4 & 3648 & 2861 & 0.7842 & 0.6322 & 0.8242 & 0.8550 & 1.7601 & 0.8482 & 1.7743 \\
\hline 5 & 42,069 & 25,038 & 0.5952 & 0.5678 & 0.9773 & 0.8280 & 1.2953 & 0.8091 & 1.3256 \\
\hline 6 & 48,987 & 34,011 & 0.6943 & 0.6166 & 1.0416 & 1.1269 & 0.9593 & 1.1227 & 0.9629 \\
\hline 7 & 35,956 & 22,112 & 0.6150 & 0.5735 & 1.0102 & 0.8492 & 1.2500 & 0.8788 & 1.2078 \\
\hline 8 & 35,100 & 22,874 & 0.6517 & 0.5476 & 0.8861 & 0.9441 & 1.4227 & 0.9315 & 1.4419 \\
\hline 9 & 30,582 & 18,939 & 0.6193 & 0.4851 & 1.1518 & 0.9659 & 1.1474 & 0.9783 & 1.1329 \\
\hline 10 & 50,757 & 28,625 & 0.5640 & 0.4811 & 1.0000 & 0.9443 & 1.2415 & 0.8775 & 1.3359 \\
\hline 11 & 26,936 & 21,454 & 0.7965 & 0.5385 & 1.1466 & 0.9622 & 1.3406 & 0.9615 & 1.3416 \\
\hline 12 & 10,804 & 7047 & 0.6523 & 0.5144 & 0.7069 & 0.8026 & 2.2350 & 0.8047 & 2.2292 \\
\hline 13 & 11,955 & 6996 & 0.5852 & 0.5502 & 1.3603 & 0.9054 & 0.8636 & 0.9101 & 0.8592 \\
\hline 14 & 9287 & 7205 & 0.7758 & 0.6676 & 0.7245 & 0.4737 & 3.3859 & 0.4907 & 3.2688 \\
\hline 15 & 15,971 & 14,379 & 0.9003 & 0.5982 & 0.8333 & 0.6822 & 2.6477 & 0.6651 & 2.7158 \\
\hline 16 & 10,608 & 4748 & 0.4476 & 0.6621 & 2.3825 & 0.7835 & 0.3622 & 0.8001 & 0.3547 \\
\hline 17 & 25,499 & 15,888 & 0.6231 & 0.5185 & 1.1342 & 0.9116 & 1.1624 & 0.8979 & 1.1802 \\
\hline 18 & 10,097 & 7423 & 0.7352 & 0.5903 & 1.1264 & 0.9233 & 1.1977 & 0.9165 & 1.2066 \\
\hline 19 & 8285 & 3958 & 0.4777 & 0.5220 & 1.6189 & 0.8546 & 0.6616 & 0.8621 & 0.6558 \\
\hline 20 & 6228 & 4751 & 0.7629 & 0.7717 & 1.3599 & 0.8865 & 0.8200 & 0.8732 & 0.8325 \\
\hline 21 & 50,284 & 36,733 & 0.7305 & 0.6402 & 1.3440 & 0.6876 & 1.2349 & 0.7211 & 1.1774 \\
\hline 22 & 6615 & 3910 & 0.5911 & 0.5898 & 1.2816 & 0.8878 & 0.8808 & 0.8868 & 0.8818 \\
\hline 23 & 4922 & 2844 & 0.5778 & 0.5574 & 2.1467 & 0.7660 & 0.6304 & 0.7735 & 0.6243 \\
\hline 24 & 22,458 & 16,095 & 0.7167 & 0.5919 & 1.0060 & 0.9669 & 1.2449 & 0.9678 & 1.2438 \\
\hline 25 & 5969 & 4275 & 0.7162 & 0.6365 & 0.9234 & 0.8717 & 1.3977 & 0.8686 & 1.4027 \\
\hline 26 & 3429 & 1942 & 0.5664 & 0.4559 & 1.0000 & 1.2838 & 0.9676 & 1.2906 & 0.9625 \\
\hline 27 & 2520 & 2063 & 0.8188 & 0.7687 & 1.3172 & 0.6584 & 1.2283 & 0.6535 & 1.2374 \\
\hline 28 & 2761 & 2078 & 0.7525 & 0.8223 & 1.3453 & 0.6239 & 1.0902 & 0.6200 & 1.0971 \\
\hline 29 & 2673 & 1631 & 0.6101 & 0.5135 & 0.9322 & 1.1390 & 1.1190 & 1.1329 & 1.1250 \\
\hline 30 & 14,601 & 14,368 & 0.9841 & 0.9183 & 1.0149 & 0.7824 & 1.3496 & 0.7827 & 1.3490 \\
\hline 31 & 10,208 & 7258 & 0.7110 & 0.6464 & 0.8264 & 0.9037 & 1.4729 & 0.9012 & 1.4769 \\
\hline Arithm. Average & 19,477 & 13,017 & 0.6730 & 0.5977 & 1.1318 & 0.8708 & 1.3238 & 0.8690 & 1.3261 \\
\hline Median & 10,804 & 7258 & 0.6523 & 0.5898 & 1.0102 & 0.8717 & 1.2349 & 0.8732 & 1.2078 \\
\hline Maximum & 68,347 & 41,390 & 0.9841 & 0.9183 & 2.3825 & 1.2838 & 3.3859 & 1.2906 & 3.2688 \\
\hline Minimum & 2520 & 936 & 0.3686 & 0.3792 & 0.6625 & 0.4737 & 0.3622 & 0.4907 & 0.3547 \\
\hline Std. Dev. & 17,780 & 11,462 & 0.1308 & 0.1155 & 0.3749 & 0.1677 & 0.6042 & 0.1641 & 0.6002 \\
\hline
\end{tabular}

therefore cost-efficient. In the rest of the cases one may obtain conflicting results. For example, Bank \#16 ranks worst regarding technical efficiency change with $T E_{S V}=2.2748$, while from the additive perspective it shows cost savings of $T E_{A}=-130$ million TWD. This, however, is an exception. The same bank presents the second largest contribution to cost reduction from an allocative perspective $A E_{S V}=0.8670$, which is compatible with cost savings of $A E_{A}=-1638$ million TWD, the fourth largest decline from the additive perspective. The pairwise Spearman correlations between the multiplicative and additive components can be found in Table 2 .

The discrepancy between the multiplicative and additive components representing technological change is much smaller. On average, technological change contributes to cost reduction by $14.15 \%$ on average, $T C_{S V}=0.8585$, just as its additive counterpart shows decreasing cost, $T C_{A}=-1587$ million TWD. Comparing these two components at the individual level, one confirms that technological progress (regress) in the multiplicative approach normally corresponds with cost decreases (increases) in the additive approach. For instance, Bank \#14, whose technological progress is the one contributing most to cost reduction, $T C_{S V}=0.4993$, reducing cost by half, also shows the largest additive cost reduction equal to $-12,649$ million TWD. As for the last two factors, capturing the activity (scale) effect and the input price structure effect, the first acts strongly against the observed reduction in costs, Act. $E_{S V} \geq 1$, while the effect of the change in input price structure is almost negligible, $I P S_{S V} \approx 1$. This corresponds with the additive decomposition.

The decomposition of cost variation by means of the cost function, as proposed by Diewert (2014) and later modified by GrifellTatjé and Lovell (2015), expressions (28)-(31) and (32)-(35), respectively, is presented in Table 5 . As the distance function does not play a role in the analysis, cost efficiency change cannot be decomposed into its technical and allocative components comparable to Tables 3 and 4 .

Cost reduction in the Taiwanese banking industry appears to be again mainly driven by the decline of input prices, as on average $I P I_{D}=0.5977$. This corresponds to the average SV input price index $I P I_{S V}=0.6378$, as reported in Table 4. As for the sources of cost reduction, all the index numbers are remarkably similar to those following from the decomposition of the SV quantity index. First we observe that Diewert's (2014) cost efficiency factor can be compared to the cost efficiency effect that results from multiplying the technical and allocative effects in Table 4. Growing technical inefficiency detracts from cost reduction, although the effect following from the SV decomposition is half of what is signaled by Diewert's factor: $C E_{D}=1.1318$ versus $T E_{S V} \times A E_{S V}=1.0595 \times 1.0141=1.0744$. The differences between the other factors compensate for this gap, though the values are very similar. Technological change contributes to cost reduction with $-12.92 \%\left(T C_{D}=0.8708\right)$, and output quantity change increases cost by $32.38 \%\left(O Q I_{D}=1.3238\right)$, the 
Table 6

More decompositions of cost variation: Expression (36), Montgomery-Vartia, and expression (40).

\begin{tabular}{|c|c|c|c|c|c|c|c|c|c|c|c|c|c|}
\hline \multirow[b]{3}{*}{ Bank } & \multirow[b]{3}{*}{$\Delta C_{A}^{0610}$} & \multirow{2}{*}{\multicolumn{2}{|c|}{ Ex. (36) }} & \multirow[b]{3}{*}{$\Delta C_{M}^{0610}$} & \multicolumn{2}{|c|}{ Montgomery-Vartia } & \multicolumn{5}{|l|}{ This paper } & \multirow{2}{*}{\multicolumn{2}{|c|}{ Ex. (40) }} \\
\hline & & & & & \multicolumn{2}{|l|}{$(38)$} & \multirow{2}{*}{$\begin{array}{l}\text { Technical } \\
\text { Efficiency } \\
\text { Effect (23') } \\
T E^{M V} \\
\end{array}$} & \multirow{2}{*}{$\begin{array}{l}\text { Allocative } \\
\text { Efficiency } \\
\text { Effect (23') } \\
A E^{M V}\end{array}$} & \multirow{2}{*}{$\begin{array}{l}\text { Technological } \\
\text { Change Effect } \\
\left(25^{\prime}\right) \\
T C^{M V}\end{array}$} & \multirow{2}{*}{$\begin{array}{l}\text { Activity } \\
\text { Effect (26') } \\
\text { Act.E } E^{M V}\end{array}$} & \multirow{2}{*}{$\begin{array}{l}\text { Input } \\
\text { Price Structure } \\
\left(27^{\prime}\right) \\
I P S^{M V}\end{array}$} & & \\
\hline & & $L M\left(C^{06}, C^{10}\right)$ & $\ln \left(C^{10} / C^{06}\right)$ & & $I P I_{M V}$ & $I Q I_{M V}$ & & & & & & $I P I$ & $I Q I$ \\
\hline 1 & -1603 & 1606 & -1.0 & 0.3686 & 0.3794 & 0.9716 & 1.0000 & 1.0533 & 0.7647 & 1.2220 & 0.9871 & -1557 & -46 \\
\hline 2 & $-26,957$ & 53,746 & -0.5 & 0.6056 & 0.4451 & 1.3607 & 1.0000 & 0.7028 & 1.4242 & 1.2449 & 1.0920 & $-43,510$ & 16,553 \\
\hline 3 & -3973 & 21,628 & -0.2 & 0.8322 & 0.7438 & 1.1189 & 0.6815 & 0.8796 & 0.8047 & 2.2781 & 1.0182 & -6403 & 2,430 \\
\hline 4 & -787 & 3239 & -0.2 & 0.7842 & 0.6595 & 1.1891 & 0.8281 & 0.8528 & 0.9090 & 1.7994 & 1.0294 & -1348 & 561 \\
\hline 5 & $-17,031$ & 32,820 & -0.5 & 0.5952 & 0.5832 & 1.0205 & 1.0000 & 0.8349 & 0.8791 & 1.3459 & 1.0331 & $-17,696$ & 665 \\
\hline 6 & $-14,976$ & 41,045 & -0.4 & 0.6943 & 0.6293 & 1.1032 & 1.0000 & 0.9139 & 1.1858 & 0.9865 & 1.0319 & $-19,007$ & 4,030 \\
\hline 7 & $-13,844$ & 28,475 & -0.5 & 0.6150 & 0.5765 & 1.0668 & 1.0000 & 0.7069 & 1.0283 & 1.3448 & 1.0913 & $-15,686$ & 1842 \\
\hline 8 & $-12,226$ & 28,552 & -0.4 & 0.6517 & 0.5857 & 1.1125 & 0.8321 & 0.9562 & 0.9522 & 1.4480 & 1.0141 & $-15,271$ & 3045 \\
\hline 9 & $-11,643$ & 24,297 & -0.5 & 0.6193 & 0.5581 & 1.1096 & 0.9474 & 1.0440 & 0.9890 & 1.1435 & 0.9920 & $-14,171$ & 2527 \\
\hline 10 & $-22,132$ & 38,640 & -0.6 & 0.5640 & 0.4798 & 1.1753 & 1.0000 & 0.9992 & 0.9412 & 1.2509 & 0.9991 & $-28,374$ & 6242 \\
\hline 11 & -5482 & 24,091 & -0.2 & 0.7965 & 0.6150 & 1.2950 & 1.0325 & 0.9394 & 0.9712 & 1.3525 & 1.0165 & $-11,710$ & 6228 \\
\hline 12 & -3757 & 8792 & -0.4 & 0.6523 & 0.5239 & 1.2450 & 0.6740 & 1.1335 & 0.7511 & 2.1888 & 0.9912 & -5683 & 1926 \\
\hline 13 & -4959 & 9255 & -0.5 & 0.5852 & 0.6232 & 0.9390 & 1.2206 & 0.8969 & 0.9220 & 0.9030 & 1.0303 & -4376 & -582 \\
\hline 14 & -2082 & 8202 & -0.3 & 0.7758 & 0.6804 & 1.1402 & 1.0000 & 0.5867 & 0.5427 & 3.4499 & 1.0379 & -3158 & 1076 \\
\hline 15 & -1592 & 15,161 & -0.1 & 0.9003 & 0.6374 & 1.4125 & 0.8810 & 0.8596 & 0.6868 & 2.6845 & 1.0116 & -6828 & 5236 \\
\hline 16 & -5860 & 7289 & -0.8 & 0.4476 & 0.7370 & 0.6073 & 2.2582 & 0.6882 & 0.8939 & 0.4122 & 1.0606 & -2224 & -3635 \\
\hline 17 & -9611 & 20,316 & -0.5 & 0.6231 & 0.6355 & 0.9804 & 0.9362 & 0.9435 & 0.9011 & 1.2048 & 1.0225 & -9210 & -401 \\
\hline 18 & -2674 & 8691 & -0.3 & 0.7352 & 0.6580 & 1.1174 & 1.0801 & 0.7952 & 0.9931 & 1.2644 & 1.0361 & -3638 & 965 \\
\hline 19 & -4327 & 5857 & -0.7 & 0.4777 & 0.6125 & 0.7799 & 1.4568 & 0.7976 & 0.9147 & 0.7030 & 1.0440 & -2871 & -1456 \\
\hline 20 & -1477 & 5456 & -0.3 & 0.7629 & 0.7747 & 0.9848 & 0.9466 & 1.2397 & 0.9424 & 0.8551 & 1.0413 & -1393 & -84 \\
\hline 21 & $-13,550$ & 43,154 & -0.3 & 0.7305 & 0.6795 & 1.0751 & 1.0000 & 0.6553 & 0.9555 & 1.4458 & 1.1875 & $-16,675$ & 3124 \\
\hline 22 & -2709 & 5144 & -0.5 & 0.5911 & 0.6885 & 0.8585 & 1.1823 & 0.8586 & 0.9101 & 0.9123 & 1.0185 & -1920 & -785 \\
\hline 23 & -2078 & 3789 & -0.5 & 0.5778 & 0.6138 & 0.9413 & 1.8636 & 0.8253 & 0.8542 & 0.6784 & 1.0560 & -1849 & -229 \\
\hline 24 & -6363 & 19,100 & -0.3 & 0.7167 & 0.6444 & 1.1121 & 0.9426 & 0.9516 & 0.9729 & 1.2574 & 1.0135 & -8392 & 2029 \\
\hline 25 & -1694 & 5075 & -0.3 & 0.7162 & 0.6777 & 1.0568 & 0.9011 & 0.8313 & 0.9315 & 1.4500 & 1.0445 & -1975 & 281 \\
\hline 26 & -1487 & 2615 & -0.6 & 0.5664 & 0.4739 & 1.1950 & 1.0000 & 1.2565 & 1.1018 & 0.9139 & 0.9445 & -1953 & 466 \\
\hline 27 & -457 & 2284 & -0.2 & 0.8188 & 0.8139 & 1.0060 & 1.4004 & 0.5949 & 0.8098 & 1.3507 & 1.1041 & -470 & 14 \\
\hline 28 & -683 & 2403 & -0.3 & 0.7525 & 0.8342 & 0.9021 & 0.9365 & 0.8796 & 0.7978 & 1.2227 & 1.1227 & -436 & -248 \\
\hline 29 & -1042 & 2109 & -0.5 & 0.6101 & 0.4358 & 1.4001 & 0.8787 & 1.4436 & 1.0615 & 1.0779 & 0.9648 & -1752 & 710 \\
\hline 30 & -233 & 14,484 & 0.0 & 0.9841 & 0.9641 & 1.0207 & 0.9867 & 0.8538 & 0.8345 & 1.3973 & 1.0390 & -530 & 297 \\
\hline 31 & -2950 & 8649 & -0.3 & 0.7110 & 0.8081 & 0.8798 & 0.9591 & 0.6191 & 0.9410 & 1.5172 & 1.0379 & -1842 & -1108 \\
\hline $\begin{array}{l}\text { Arithm. } \\
\text { Average }\end{array}$ & -6459 & 15,999 & -0.4 & 0.6730 & 0.6378 & 1.0702 & 1.0589 & 0.8901 & 0.9215 & 1.3647 & 1.0359 & $-8,126$ & 1667 \\
\hline Median & -3757 & 8792 & -0.4 & 0.6523 & 0.6355 & 1.0751 & 1.0000 & 0.8596 & 0.9220 & 1.2574 & 1.0319 & -3638 & 665 \\
\hline Maximum & -233 & 53,746 & 0.0 & 0.9841 & 0.9641 & 1.4125 & 2.2582 & 1.4436 & 1.4242 & 3.4499 & 1.1875 & -436 & 16,553 \\
\hline Minimum & $-26,957$ & 1606 & -1.0 & 0.3686 & 0.3794 & 0.6073 & 0.6740 & 0.5867 & 0.5427 & 0.4122 & 0.9445 & $-43,510$ & -3635 \\
\hline Std. Dev. & 6868 & 14,321 & 0.2 & 0.1308 & 0.1266 & 0.1755 & 0.3164 & 0.1957 & 0.1542 & 0.6035 & 0.0471 & 9626 & 3528 \\
\hline
\end{tabular}

corresponding effects in the previous decomposition being $-14.15 \%$ and $32.95 \%$, respectively. Also, as expected given that they simply interchange asymmetries, the technological change and output quantity indices of Grifell-Tatjé and Lovell (2015) are almost identical on average and at the individual level: $T C_{G L}=0.8690$ and $O Q I_{G L}=1.3261$.

Finally, the decompositions of the additive and multiplicative forms of cost variation as presented in Section 5 are reported in Table 6. Here the additive cost reduction is decomposed in two factors, the logarithmic mean of base and comparison period cost and the logarithm of their ratio, expression (36). While the first is not subject to decomposition, the second can be decomposed by taking the logarithms of the SV input price and quantity indices, $\ln I P I_{S V}$ and $\ln I Q I_{S V}$. Subsequently, $\ln I Q I_{S V}$ can be further decomposed by taking the logarithms of all the factors presented in Table 4, corresponding to expressions (23) and (25)-(27). We leave the exercise to the interested reader as this transformation does not alter our findings regarding the sources of cost reduction in the Taiwanese banking industry.

As for the Montgomery-Vartia (MV) decomposition of the cost ratio, expression (38), in input price and quantity index numbers, $I P I_{M V}$ and $I Q I_{M V}$, we observe that they are equal to the their SV counterparts up to the third decimal place. Hence we conclude that in this particular empirical application, the use of the alternative sets of weights, $\phi_{n}^{01}$ or $\psi_{n}^{01}$, does not make a significant difference. For the sake of completenesses we report the MV coun- terpart to the SV decomposition of the input quantity index. Here larger differences can be found when comparing each pair of components, particularly for the allocative efficiency effect, which captures most of the difference: $A E_{S V}=1.0141$ versus $A E_{M V}=0.8901$ (their Spearman correlation is $\rho\left(A E_{S V}, A E_{M V}\right)=0.5777$, which is statistically significant). In general, however, the two decompositions are compatible. The input price structure effect shows more volatility in Table 6 than in Table 4.

The alternative decomposition in expression (40) yields input price and quantity indicators comparable to the Bennet indicators in Table 3. The outcomes are remarkably similar on average, with slight variations for individual banks; a large decrease of input prices and a mild increase in input quantities.

\section{Conclusion}

A firm's cost variation through time can be expressed by a difference as well as a ratio. The asymmetric decomposition of the cost difference proposed by Grifell-Tatjé and Lovell (2000) could be replaced by a symmetric one. We also provided a structurally identical decomposition of the cost ratio. Using the powerful tool of the logarithmic mean, four additional decompositions could be developed, two for the cost difference and two for the cost ratio. All in all, the cost variation can be decomposed in at least six structurally identical, but empirically slightly different ways. The choice between them is pretty much a matter of taste, though it seems 
that generally managers prefer additive decompositions (providing money amounts) and economists prefer multiplicative decompositions (providing percentages).

Given data from a (balanced) panel of firms, all the necessary ingredients for the computation of the various decompositions can be obtained by using linear programming techniques. In this paper a small dataset of Taiwanese banks over the years 2006-2010 has been used to illustrate the empirical differences between the various decompositions.

It appeared that on average the additive Bennet price and quantity indicators correspond closely to their multiplicative SatoVartia and Montgomery-Vartia counterparts. All these measures signal that the overall cost reduction in the industry was driven by input prices, and partially offset by input quantities. Also, one should notice that at the level of individual production units additive and multiplicative measures may yield different results, notably regarding the direction of technological change and the activity effect. Especially the local nature of technological change as measured via the cost function could be a topic for further investigation. Is this specific for this set of banks and/or construction of data - Recall the huge dispersions! - , or is this somehow due to the use of DEA techniques in the cost function approach?

\section{References}

Álvarez, I., Barbero, J., \& Zofío, J. L. (2019). A data envelopment analysis toolbox for MATLAB. Journal of Statistical Software, to appear. Available from http://www. deatoolbox.com.
Balk, B. M. (1998). Industrial price, quantity, and productivity indices: the micro-economic theory and an application. Boston/Dordrecht/London: Kluwer Academic Publishers.

Balk, B. M. (2008). Price and quantity index numbers: Models for measuring aggregate change and difference. Cambridge University Press, New York.

Balk, B. M., \& Zofío, J. L. (2018). The many decompositions of total factor productivity change. ERIM Report Series Research in Management, No. ERS-2018-003-LIS. Erasmus Research Institute of Management, Erasmus University, Rotterdam. Available from http://hdl.handle.net/1765/104721.

Brea-Solís, H., Casadesus-Masanell, R., \& Grifell-Tatjé, E. (2015). Business model evaluation: Quantifying walmart's sources of advantage. Strategic Entrepreneurship Journal, 9, 12-33.

Diewert, W. E. (2014). Decompositions of profitability change using cost functions. Journal of Econometrics, 183, 58-66.

Diewert, W. E., \& Fox, K. J. (2018). A decomposition of US business sector TFP growth into technical progress and cost efficiency components. Journal of Productivity Analysis, 50, 71-84.

Grifell-Tatjé, E., \& Lovell, C. A. K. (2000). Cost and productivity. Managerial and Decision Economics, 21, 19-30.

Grifell-Tatjé, E., \& Lovell, C. A. K. (2003). The managers versus the consultants. Scandinavian Journal of Economics, 105, 119-138.

Grifell-Tatjé, E., \& Lovell, C. A. K. (2015). Productivity accounting: The economics of business performance. Cambridge University Press, New York.

Juo, J.-C., Fu, T.-T., Yu, M.-M., \& Lin, Y. H. (2015). Profit-oriented productivity change. Omega, 57, 176-187.

Reyna, A. M., \& Fuentes, H. J. (2018). A cost efficiency analysis of the insurance industry in mexico. Journal of Productivity Analysis, 49, 49-64.

Sealey, C. W., \& Lindley, J. T. (1977). Inputs, outputs, and a theory of production and cost at depository financial institutions. The Journal of Finance, 32, 1251-1266. 